\title{
Sleep disturbance: a potential target to improve symptoms and quality of life in those living with psychosis
}

\section{Sleep that knits up the ravelled sleeve of care, the death of each day's life, sore labour's bath, balm of hurt minds, great nature's second course, chief nourisher in life's feast}

\author{
C. Boland ${ }^{1,2, *}$ (D) , P. Gallagher ${ }^{3}$ and M. Clarke ${ }^{3,4}$ \\ ${ }^{1}$ St James's Hospital, Dublin, Ireland \\ 2 Department of Psychiatry, Trinity College Dublin, Ireland \\ ${ }^{3}$ Detect Early Intervention in Psychosis Service, Avila House, Carysfort Avenue, Blackrock, Dublin, Ireland \\ ${ }^{4}$ Department of Psychiatry, University College Dublin, Dublin, Ireland
}

\begin{abstract}
Sleep has been shown to impact on both physical and mental health, and sleep problems present a considerable burden for individuals and society. There appears to be a complex bidirectional relationship between sleep disturbance and psychiatric symptoms, each potentially influencing the other. In particular, sleep disorders have been associated with more severe symptoms and are predictive of relapse in those with psychotic disorders. This article discusses the relationship between psychosis and insomnia, sleep apnoea, nightmares, circadian rhythm abnormalities and the impact of medications on these relationships. We also discuss the clinical implications of the relationship between sleep disturbance and psychotic disorders along with potential targets for intervention.
\end{abstract}

Received 22 February 2019; Revised 29 October 2019; Accepted 19 November 2019; First published online 14 January 2020

Key words: Mental health, psychotic disorders, quality of life, serious mental illness, sleep.

\section{Introduction}

Sleep plays an important role in memory consolidation, emotional regulation, immune function and metabolic homeostasis (Baglioni et al. 2010; Irwin et al. 2010; Payne \& Kensinger, 2010; Xie et al. 2013). Sleep disturbance may represent an aetiological factor and symptom of many psychiatric disorders (Baglioni et al. 2011; Anderson \& Bradley, 2013). Insomnia, the most researched sleep disorder is common, severe and treatable in patients with serious mental illness (Taylor \& Pruiksma, 2014) with the prevalence rates of 16-44\% (Lieberman et al. 2005; Xiang et al. 2009; Palmese et al. 2011; Subramaniam et al. 2018) compared to $3-6 \%$ in the general population (Calem et al. 2012). Many patients report sleep disturbance as a warning sign of relapse in psychotic symptoms (Harvey, 2008; Freeman et al. 2009). Sleep disorders in early psychosis have been associated with increased psychotic experiences, anxiety, depression, fatigue and lower quality of life (Reeve et al. 2019).

*Address for correspondence: C. Boland, St James's hospital, Dublin, Ireland. (Email: bolandc2@tcd.ie)

\section{Sleep disturbance in psychosis}

Sleep disturbance is found in $30-80 \%$ of patients with psychosis (Tandon et al. 1992; Keshavan \& Tandon, 1993; Cohrs, 2008). It is a core feature of bipolar affective disorder (BPAD) (World Health Organization, 1992) and commonly occurs during episodes of mania and depression. Sleep disturbance may continue during inter-episode euthymic periods. Such baseline sleep disturbance is associated with a poorer prognosis (Kaplan et al. 2011; Sylvia et al. 2018). Insomnia may be a causal factor in the occurrence of psychotic experiences and is inversely correlated with quality of life (Xiang et al. 2009; Freeman et al. 2010; Reeve et al. 2015). Sleep difficulties, particularly insomnia, are associated with more severe psychotic symptoms in patients with schizophrenia and are predictive of relapse and transition from 'at risk mental state' to first-episode psychosis (Poulin et al. 2003; Reeve et al. 2015). Insomnia may frequently co-occur with nightmares, circadian dysfunction, parasomnias, etc. in individuals with schizophrenia (Chiu et al. 2016). Studies have shown an association between insomnia and suicidal ideation, suicidal attempts, completed suicide and psychopathology in patients with schizophrenia (Pompili et al. 2009; Li et al. 2016; Miller et al. 2019). 
Approximately $10-55 \%$ of people with schizophrenia report frequent nightmares (Mume, 2009; Michels et al. 2014; Sheaves et al. 2015) compared to the general population rate of approximately 2-6\% (Li et al. 2010; Sandman et al. 2013). The continuity hypothesis of dreaming suggests that waking life experiences are reflected in dreams under particular conditions (Schredl, 2003). A study on acutely psychotic inpatients found that there was continuity between dream and waking mentation for specific single recurring delusional themes (grandiosity and religion), suggesting an association between specific delusional contents and dreams (D'Agostino et al. 2013). Nightmares have been associated with increased suicidal ideation and behaviour (Pigeon et al. 2012; Nadorff et al. 2016; Titus et al. 2018). Comorbid nightmares and insomnia were associated with an increased suicide risk above either disorder individually in people with schizophrenia (Li et al. 2016).

Rates of obstructive sleep apnoea (OSA) are elevated in individuals with schizophrenia and around 15\% demonstrate clinically significant symptoms (Anderson et al. 2002). OSA may be mediated by weight gain, neuroleptic medication and lifestyle factors. Marked circadian rhythm abnormalities have been shown in schizophrenia (Wulff et al. 2012) and BPAD (Millar et al. 2004; Jones et al. 2005). This may be due to dopamine dysregulation (Yates, 2016). Circadian rhythm disturbance has been associated with elevated rates of cancer, diabetes, cardiovascular disease and obesity (Touitou et al. 2017). It can increase risk of accidents, errors in the workplace (Folkard et al. 2005; Van Dongen et al. 2016) and impact on personal life and general well-being (James et al. 2017). Given the widespread potential impact, treatment of circadian rhythm disturbance is an important target for intervention (Lewis et al. 2016; Yates, 2016).

\section{Neurophysiological abnormalities}

A number of sleep parameters, for example, amount of slow-wave sleep (SWS) and Rapid Eye Movement (REM) latency, are correlated with clinical variables in schizophrenia, including severity of illness, positive symptoms, negative symptoms, neurocognitive impairment and brain structure (Poulin et al. 2003; Chouinard et al. 2004). Memory consolidation has been shown to be impaired in schizophrenia and positively correlated with sleep efficiency and the amount of SWS (Goder et al. 2004). Decreased slow-wave density has been reported in acutely psychotic patients (Ganguli et al. 1987; Keshavan et al. 1998) and firstepisode psychosis is inversely correlated with positive symptom severity (Kaskie et al. 2019a). This is in contrast to more stable patients with schizophrenia
(Goder et al. 2015). Deficits in sleep spindle activity have been consistently shown in first-episode psychosis and schizophrenia; however, slow-wave deficits have been less consistently found (Castelnovo et al. 2018; Kaskie et al. 2019b). Unaffected first degree relatives of those with schizophrenia have been shown to have non-REM sleep abnormalities including reduced spindle activity and decreased slow-wave amplitude (D'Agostino et al. 2018). The authors propose that disrupted cortical synchronisation (slow-wave activity) may increase risk and that thalamic dysfunction (reduced spindle activity) may also be necessary to develop schizophrenia. Sleep abnormalities present in psychosis may interfere with memory consolidation and influence cognitive function, mood and psychotic symptoms. However, further research is necessary to determine the direction of associations.

\section{Medications}

Sedatives and antipsychotics are commonly prescribed for sleep problems. However, sedative medications have limited effectiveness in chronic insomnia and have been associated with nightmares (Pagel \& Helfter, 2003), risks of drug interaction, dependence and adverse side effects (Holbrook et al. 2000; Cates et al. 2009; Takaesu et al. 2014). Both first and second generation antipsychotics (except risperidone) have been associated with prolonged total sleep time and increased sleep efficiency in schizophrenia (Cohrs, 2008; Monti et al. 2017).

Furthermore, second generation antipsychotics reduce sleep latency and may offer some relief from chronic insomnia in those with schizophrenia (Monti et al. 2017). However, the confounding effect of antipsychotics in individual sleep disorders, particularly movement disorders and sleep-related breathing disorders, and the possibility of daytime sedation are major problems (Cohrs, 2008). This picture is complicated by antidepressants' interaction with sleep as they are often prescribed alongside antipsychotics (Wilson \& Argyropoulos, 2005).

\section{Future interventions}

Treating sleep is an important therapeutic target in psychosis. Guidelines are in place stating that clinically significant sleep disorders should be considered as comorbid diagnosis and receive independent clinical attention regardless of other conditions (APA, 2013; AASS, 2014). Cognitive behavioural therapy for insomnia (CBT-I) has an established evidence base (Trauer et al. 2015; Riemann et al. 2017), has been used to treat insomnia in psychosis and may reduce psychotic symptoms (Freeman et al. 2015; Chiu et al. 2018; 
Hwang et al. 2019). Furthermore, treatment of nightmares using proven techniques such as image rehearsal therapy or CBT for nightmares may alleviate psychotic symptoms along with nightmares themselves (Seeman, 2018; Sheaves et al. 2019).

Despite the high prevalence of sleep disorders in psychosis and improving sleep being among patients' highest priorities for treatment (Waite et al. 2015), sleep disorders are rarely addressed directly. Manifestations of daytime symptoms stemming from insomnia can be important illness indications (Cheung et al. 2014). A recent study showed that while over half of those with sleep disorders had discussed this with a clinician, almost $60 \%$ received no treatment (Reeve et al. 2019). Treatment of sleep disorders is a priority for patients with psychosis (Faulkner \& Bee, 2017). However, formal sleep assessments are rarely used and evidence-based treatments such as CBT-I are infrequently offered (Cheung et al. 2014; Rehman et al. 2017). Qualitative studies show that patients show a preference for cognitive and behavioural therapies over standard pharmacological or melatonin-based therapies for long-term sleep problems (Waters et al. 2015; Chiu et al. 2016; Faulkner \& Bee, 2017). An important consideration is that people with schizophrenia are likely to require support with motivation and further psychological interventions to address unhelpful cognitions about sleep (Chiu et al. 2016). A recent adaptation of CBT-I in psychosis incorporates 12 main factors which disrupt sleep in those with schizophrenia and patients' concerns regarding treatment (Waite et al. 2016). This may act as a building block to future therapies.

Light therapies represent a potential mechanism to improve circadian rhythm sleep disorders (Faulkner et al. 2019). However, further research is needed in those with psychosis. The majority of females with schizophrenia who have OSA are never diagnosed clinically, despite the potential benefits of continuous positive airway pressure on cardiometabolic parameters and cognitive impairment (Seeman, 2014). Increased awareness of symptoms of hypersomnia such as excessive daytime sleepiness and extended nocturnal sleep period along with lack of energy, depression and insomnia in this population may help improve clinical suspicion (Hawley, 2006).

Evidence to date can only confirm that the relationship between sleep disorders and psychosis is at an associative level (Reeve et al. 2015; Davies et al. 2017). Nonetheless, sleep disturbance in psychosis should be a target for intervention, since it is a source of distress and impaired functioning for which effective treatments exist (Waite et al. 2016; Freeman et al. 2017). However, as different sleep disorders require different and specific interventions, establishing the prevalence and types of sleep disorders and the acceptability of potential interventions should now be regarded as a crucial avenue of investigation in psychosis research.

\section{Acknowledgements}

None.

\section{Financial Support}

This research received no specific grant from any funding agency, commercial or not-for-profit sectors.

\section{Conflict of Interest}

The authors have no conflicts of interest to declare.

\section{Ethical Standards}

The authors assert that all procedures contributing to this work comply with the ethical standards of the relevant national and institutional committee on human experimentation with the Helsinki Declaration of 1975, as revised in 2008. The authors assert that ethical approval for publication of this paper was not required by their local REC.

\section{References}

AASS (American Academy of Sleep Medicine) (2014). International Classification of Sleep Disorders, 3rd edn. American Academy of Sleep Medicine: Darien, IL.

Anderson KN, Bradley AJ (2013). Sleep disturbance in mental health problems and neurodegenerative disease. Nature and Science of Sleep 5, 61-75.

Anderson KN, Waton T, Armstrong D, Watkinson HM, Mackin P (2002). Sleep disordered breathing in community psychiatric patients. European Journal of Psychiatry 26, 86-95.

APA (American Psychiatric Association) (2013). Diagnostic and Statistical Manual of Mental Disorders, 5th edn. American Psychiatric Association: Washington, DC.

Baglioni C, Battagliese G, Feige B, Spiegelhalder K, Nissen C, Voderholzer U, Lombardo C, Riemann, D (2011). Insomnia as a predictor of depression: a metaanalytic evaluation of longitudinal epidemiological studies. Journal of Affective Disorders 135, 10-19.

Baglioni C, Spiegelhalder K, Lombardo C, Riemann D (2010). Sleep and emotions: a focus on insomnia. Sleep Medicine Reviews 14, 227-238.

Calem M, Bisla J, Begum A, Dewey M, Bebbington PE, Brugha T, Cooper C, Jenkins R, Lindesay J, McManus S, Meltzer H, Spiers N, Weich S, Stewart R (2012). Increased prevalence of insomnia and changes in hypnotics use in England over 15 years: analysis of the 1993, 2000, and 2007 national psychiatric morbidity surveys. Sleep 35, 377-384.

Castelnovo A, Graziano B, Ferrarelli F, D'Agostino A (2018). Sleep spindles and slow waves in schizophrenia 
and related disorders: main findings, challenges and future perspectives. European Journal of Neuroscience 48, $2738-2758$.

Cates ME, Jackson CW, Feldman JM, Stimmel AE, Woolley TW (2009). Metabolic consequences of using low-dose quetiapine for insomnia in psychiatric patients. Community Mental Health Journal 45, 251-254.

Cheung JM, Bartlett DJ, Armour CL, Glozier N, Saini B (2014). Insomnia patients' help-seeking experiences. Behavioral Sleep Medicine 12, 106-122.

Chiu VW, Ree M, Janca A, Iyyalol R, Dragovic M, Waters F (2018). Sleep profiles and CBT-I response in schizophrenia and related psychoses. Psychiatry Research 268, 279-287.

Chiu VW, Ree M, Janca A, Waters F (2016). Sleep in schizophrenia: exploring subjective experiences of sleep problems, and implications for treatment. Psychiatric Quarterly 87, 633-648.

Chouinard S, Poulin J, Stip E, Godbout R (2004). Sleep in untreated patients with schizophrenia: a meta-analysis. Schizophrenia Bulletin 30, 957-967.

Cohrs S (2008). Sleep disturbances in patients with schizophrenia: impact and effect of antipsychotics. CNS Drugs 22, 939-962.

D'Agostino A, Aletti G, Carboni M, Cavallotti S, Limosani I, Manzone M, Scarone S (2013). Are delusional contents replayed during dreams? Consciousness and Cognition, 22, 708-715.

D'Agostino A, Castelnovo A, Cavallotti S, Casetta C, Marcatili M, Gambini O, Canevini M, Tononi G, Riedner B, Ferrarelli F, Sarasso S (2018). Sleep endophenotypes of schizophrenia: slow waves and sleep spindles in unaffected first-degree relatives. NPJ Schizophrenia 4, 2.

Davies G, Haddock G, Yung AR, Mulligan LD, Kyle SD (2017). A systematic review of the nature and correlates of sleep disturbance in early psychosis. Sleep Medicine Reviews 31, 25-38.

Faulkner S, Bee P (2017). Experiences, perspectives and priorities of people with schizophrenia spectrum disorders regarding sleep disturbance and its treatment: a qualitative study. BMC Psychiatry 17, 158.

Faulkner SM, Bee PE, Meyer N, Dijk DJ, Drake RJ (2019). Light therapies to improve sleep in intrinsic circadian rhythm sleep disorders and neuro-psychiatric illness: a systematic review and meta-analysis. Sleep Medicine Reviews 46, 108-123.

Folkard S, Lombardi DA, Tucker PT (2005). Shiftwork: safety, sleepiness and sleep. Industrial Health 43, 20-23.

Freeman D, Brugha T, Meltzer H, Jenkins R, Stahl D, Bebbington P (2010). Persecutory ideation and insomnia: findings from the second British national survey of psychiatric morbidity. Journal of Psychiatric Research 44, 1021-1026.

Freeman D, Pugh K, Vorontsova N, Southgate L (2009). Insomnia and paranoia. Schizophrenia Research 108, 280-284.

Freeman D, Sheaves B, Goodwin GM, Yu LM, Nickless A, Harrison PJ et al. (2017). The effects of improving sleep on mental health (OASIS): a randomised controlled trial with mediation analysis. Lancet Psychiatry 4, 749-758.

Freeman D, Waite F, Startup H, Myers E, Lister R, McInerney J, Harvey AG, Geddes J, Zaiwalla Z, Luengo-Fernandez R, Foster R, Clifton L, Yu LM (2015). Efficacy of cognitive behavioural therapy for sleep improvement in patients with persistent delusions and hallucinations (BEST): a prospective, assessor-blind, randomised controlled pilot trial. Lancet Psychiatry 2, 975-983.

Ganguli R, Reynolds CF 3rd, Kupfer DJ (1987). Electroencephalographic sleep in young, never-medicated schizophrenics. A comparison with delusional and nondelusional depressives and healthy controls. Archives of General Psychiatry 44, 36-44.

Goder R, Boigs M, Braun S, Friege L, Fritzer G, Aldenhoff JB, Hinze-Selch D (2004). Impairment of visuospatial memory is associated with decreased slow wave sleep in schizophrenia. Journal of Psychiatric Research 38, 591-599.

Goder R, Graf A, Ballhausen F, Weinhold S, Baier PC, Junghanns K, Prehn-Kristensen A (2015). Impairment of sleep-related memory consolidation in schizophrenia: relevance of sleep spindles? Sleep Medicine 16, 564-569.

Harvey AG (2008). Sleep and circadian rhythms in bipolar disorder: seeking synchrony, harmony, and regulation. American Journal of Psychiatry 165, 820-829.

Hawley CJ (2006). Excessive daytime sleepiness in psychiatry: a relevant focus for clinical attention and treatment? International Journal of Psychiatry in Clinical Practice 10, 117-123.

Holbrook AM, Crowther R, Lotter A, Cheng C, King D (2000). Meta-analysis of benzodiazepine use in the treatment of insomnia. Canadian Medical Association Journal 162, 225-233.

Hwang DK, Nam M, Lee YG (2019). The effect of cognitive behavioral therapy for insomnia in schizophrenia patients with sleep disturbance: a non-randomized, assessor-blind trial. Psychiatry Research 274, 182-188.

Irwin MR, Carrillo C, Olmstead R (2010). Sleep loss activates cellular markers of inflammation: sex differences. Brain, Behaviour and Immunity 24, 54-57.

James SM, Honn K, Gaddameedhi S, Van Dongen HPA (2017). Shift work: disrupted circadian rhythms and sleep-implications for health and well-being. Current Sleep Medicine Reports 3, 104-112.

Jones SH, Hare DJ, Evershed K (2005). Actigraphic assessment of circadian activity and sleep patterns in bipolar disorder. Bipolar Disorder 7, 176-186.

Kaplan KA, Gruber J, Eidelman P, Talbot LS, Harvey AG (2011). Hypersomnia in inter-episode bipolar disorder: does it have prognostic significance. Journal of Affective Disorders 132, 438-444.

Kaskie RE, Gill KM, Ferrarelli F (2019a). Reduced frontal slow wave density during sleep in first-episode psychosis. Schizophrenia Research 206, 318-324.

Kaskie RE, Graziano B, Ferrarelli F (2019b). Topographic deficits in sleep spindle density and duration point to frontal thalamo-cortical dysfunctions in first-episode psychosis. Journal of Psychiatry Research 113, 39-44. 
Keshavan MS, Reynolds CF 3rd, Miewald MJ, Montrose DM, Sweeney JA, Vasko RC Jr, Kupfer DJ (1998). Delta sleep deficits in schizophrenia: evidence from automated analyses of sleep data. Archives of General Psychiatry 55, 443-448.

Keshavan MS, Tandon R (1993). Sleep abnormalities in schizophrenia: pathophysiological significance. Psychological Medicine 23, 831-835.

Lewis KJ, Foster RG, Jones IR (2016). Is sleep disruption a trigger for postpartum psychosis? British Journal of Psychiatry 208, 409-411.

Li SX, Lam SP, Zhang J, Yu MWM, Chan JWY, Chan CSY, Espie CA, Freeman D, Mason O, Wing YK (2016). Sleep disturbances and suicide risk in an 8-year longitudinal study of schizophrenia-spectrum disorders. Sleep 39, $1275-1282$.

Li SX, Zhang B, Li AM, Wing YK (2010). Prevalence and correlates of frequent nightmares: a community-based 2-phase study. Sleep 33, 774-780.

Lieberman JA, Stroup TS, McEvoy JP, Swartz MS, Rosenheck RA, Perkins DO, Keefe RSE, Davis SM, Davis CE. Lebowitz BD, Severe J, Hsiao JK (2005). Effectiveness of antipsychotic drugs in patients with chronic schizophrenia. New England Journal of Medicine 353, 1209-1223.

Michels F, Schilling C, Rausch F, Eifler S, Zink M, Meyer-Lindenberg A, Schredl M (2014). Nightmare frequency in schizophrenic patients, healthy relatives of schizophrenic patients, patients at high risk states for psychosis, and healthy controls. International Journal of Dream Research 7, 9-13.

Millar A, Espie CA, Scott J (2004). The sleep of remitted bipolar outpatients: a controlled naturalistic study using actigraphy. Journal of Affective Disorders 80, 145-153.

Miller BJ, Parker CB, Rapaport MH, Buckley PF, McCall WV (2019). Insomnia and suicidal ideation in non-affective psychosis. Sleep 42, 215.

Monti JM, Torterolo P, Pandi Perumal SR (2017). The effects of second generation antipsychotic drugs on sleep variables in healthy subjects and patients with schizophrenia. Sleep Medicine Reviews 33, 51-57.

Mume CO (2009). Nightmares in schizophrenic and depressed patients. European Journal of Psychiatry 23, 177-183.

Nadorff MR, Pearson MD, Golding S (2016). Explaining the relation between nightmares and suicide. Journal of Clinical Sleep Medicine 12, 289-290.

Pagel JF, Helfter P (2003). Drug induced nightmares-an etiology based review. Human Psychopharmacology 18, 59-67.

Palmese LB, DeGeorge PC, Ratliff JC, Srihari VH, Wexler BE, Krystal AD, Tek C (2011). Insomnia is frequent in schizophrenia and associated with night eating and obesity. Schizophrenia Research 133, 238-243.

Payne JD, Kensinger EA (2010). Sleep's role in the consolidation of emotional episodic memories. Current Directions in Psychological Science 19, 290-295.

Pigeon WR, Pinquart M, Conner K (2012). Meta-analysis of sleep disturbance and suicidal thoughts and behaviors. Journal of Clinical Psychiatry 73, 1160-1167.
Pompili M, Lester D, Grispini A, Innamorati M, Calandro F, Iliceto P, De Pisa E, Tatarelli R, Girardi P (2009). Completed suicide in schizophrenia: evidence from a case-control study. Psychiatry Research 167, 251-257.

Poulin J, Daoust AM, Forest G, Stip E, Godbout R (2003). Sleep architecture and its clinical correlates in first episode and neuroleptic-naive patients with schizophrenia. Schizophrenia Research 62, 147-153.

Reeve S, Sheaves B, Freeman D (2015). The role of sleep dysfunction in the occurrence of delusions and hallucinations: a systematic review. Clinical Psychology Review 42, 96-115.

Reeve S, Sheaves B, Freeman D (2019). Sleep disorders in early psychosis: Incidence, severity and association with clinical symptoms. Schizophrenia Bulletin 45, 287-295.

Rehman A, Waite F, Sheaves B, Biello S, Freeman D, Gumley A (2017). Clinician perceptions of sleep problems, and their treatment, in patients with nonaffective psychosis. Psychosis 9, 129-139.

Riemann D, Baglioni C, Bassetti C, Bjorvatn B, Dolenc Groselj L, Ellis JG et al. (2017). European guideline for the diagnosis and treatment of insomnia. Journal of Sleep Research 26, 675-700.

Sandman N, Valli K, Kronholm E, Ollila HM, Revonsuo A, Laatikainen T, Paunio T (2013). Nightmares: prevalence among the Finnish general adult population and war veterans during 1972-2007. Sleep 36, 1041-1050.

Schredl M (2003). Continuity between waking and dreaming: a proposal for a mathematical model. Sleep and Hypnosis 5, 38-52.

Seeman MV (2014). Diagnosis and treatment of sleep apnoea in women with schizophrenia. Journal of Mental Health 23, 191-196.

Seeman MV (2018). Successful treatment of nightmares may reduce psychotic symptoms in schizophrenia. World Journal of Psychiatry 8, 75-78.

Sheaves B, Holmes EA, Rek S, Taylor KM, Nickless A, Waite F, Germain A, Espie CA, Harrison PJ, Foster R, Freeman D (2019). Cognitive behavioural therapy for nightmares for patients with persecutory delusions (Nites): an assessor-blind, pilot randomized controlled trial. Canadian Journal of Psychiatry 64, 686-696. [Epub ahead of print] Accessed 7 August 2019.

Sheaves B, Onwumere J, Keen N, Stahl D, Kuipers E (2015). Nightmares in patients with psychosis: the relation with sleep, psychotic, affective, and cognitive symptoms. Canadian Journal of Psychiatry 60, 354-361.

Subramaniam M, Abdin E, Shahwan S, Satghare P, Vaingankar JA, Rama Sendren J, Picco L, Chua BY, Ng BT, Chong SA, Verma S (2018). Prevalence, correlates and outcomes of insomnia in patients with first episode psychosis from a tertiary psychiatric institution in Singapore. General Hospital Psychiatry 51, 15-21.

Sylvia LG, Chang WC, Kamali M, Tohen M, Kinrys G, Deckersbach T, Calabrese JR, Thase ME, Reilly-Harrington N, Bobo WV, Kocsis JH, McInnis MG, Bowden CL, Ketter TA, Friedman ES, Shelton RC, McElroy SL, Gao K, Rabideau DJ, Nierenberg AA (2018). Sleep disturbance may impact treatment outcome 
in bipolar disorder: a preliminary investigation in the context of a large comparative effectiveness trial. Journal of Affective Disorders 225, 563-568.

Takaesu Y, Komada Y, Asaoka S, Kagimura T, Inoue Y (2014). Factors associated with long-term use of hypnotics among patients with chronic insomnia. PloS One $\mathbf{9}$, e113753.

Tandon R, Shipley JE, Taylor S, Greden JF, Eiser A, DeQuardo J, Goodson J (1992). Electroencephalographic sleep abnormalities in schizophrenia. Relationship to positive/negative symptoms and prior neuroleptic treatment. Archives of General Psychiatry 49, 185-194.

Taylor DJ, Pruiksma KE (2014). Cognitive and behavioural therapy for insomnia (CBT-I) in psychiatric populations: a systematic review. International Review of Psychiatry 26, 205-213.

Titus CE, Speed KJ, Cartwright PM, Drapeau CW, Heo Y, Nadorff MR (2018). What role do nightmares play in suicide? A brief exploration. Current Opinion in Psychology 22, 59-62.

Touitou Y, Reinberg A, Touitou D (2017). Association between light at night, melatonin secretion, sleep deprivation, and the internal clock: health impacts and mechanisms of circadian disruption. Life Sciences 173, 94-106.

Trauer JM, Qian MY, Doyle JS, Rajaratnam SM, Cunnington D (2015). Cognitive behavioural therapy for chronic insomnia: a systematic review and meta-analysis. Annals of Internal Medicine 163, 191-204.

Van Dongen HPA, Balkin TJ, Hursh SR (2016). Performance deficits during sleep loss and their operational consequences. In Principles and Practice of Sleep Medicine (ed. M Kryger, T Roth and WC Dement), pp. 682-688. Academic: Philadelphia.

Waite F, Evans N, Myers E, Startup H, Lister R, Harvey A, Freeman D (2015). The patient experience of sleep problems and their treatment in the context of current delusions and hallucinations. Psychology and Psychotherapy: Theory, Research and Practice 89, 181-193.

Waite F, Myers E, Harvey AG, Espie CA, Startup H, Sheaves B, Freeman D (2016). Treating sleep problems in patients with schizophrenia. Behavioural and Cognitive Psychotherapy 44, 273-287.

Waters F, Chiu VW, Janca A, Atkinson A, Ree M (2015). Preferences for different insomnia treatment options in people with schizophrenia and related psychoses: a qualitative study. Frontiers in Psychology 6, 990.

Wilson S, Argyropoulos S (2005). Antidepressants and sleep: a qualitative review of the literature. Drugs 65, 927-947.

World Health Organization (1992). The ICD-10 Classification of Mental and Behavioural Disorders: Clinical Descriptions and Diagnostic Guidelines. World Health Organization: Geneva.

Wulff K, Dijk DJ, Middleton B, Foster RG, Joyce EM (2012). Sleep and circadian rhythm disruption in schizophrenia. British Journal of Psychiatry 200, 308-316.

Xiang YT, Weng YZ, Leung CM, Tang WK, Lai KY, Ungvari GS (2009). Prevalence and correlates of insomnia and its impact on quality of life in Chinese schizophrenia patients. Sleep 32, 105-109.

Xie L, Kang H, Xu Q, Chen M, Liao Y, Thiyagarajan M, O'Donnell J, Christensen DJ, Nicholson C, Iliff JJ, Takano T, Deane R, Nedergaard M (2013). Sleep drives metabolite clearance from the adult brain. Science 342, 373-377.

Yates NJ (2016). Schizophrenia: the role of sleep and circadian rhythms in regulating dopamine and psychosis. Reviews in the Neurosciences 27, 669-687. 